\title{
Increased IGFBP7 Expression Correlates with Poor Prognosis and Immune Infiltration in Gastric Cancer: An Integrated Bioinformatics Analysis
}

\section{Qiaoyun Zhao}

Department of Gastroenterology, The First Affiliated Hospital of Nanchang University, No.17, Yongwai Zheng Street, Donghu District, Nanchang, 330000, Jiangxi, China

\section{Rulin Zhao}

Department of Gastroenterology, The First Affiliated Hospital of Nanchang University, No.17, Yongwai Zheng Street, Donghu District, Nanchang, 330000, Jiangxi, China

\section{Conghua Song}

Department of Gastroenterology, The First Affiliated Hospital of Nanchang University, No.17, Yongwai Zheng Street, Donghu District, Nanchang, 330000, Jiangxi, China

\section{Huan Wang}

Department of Gastroenterology, The First Affiliated Hospital of Nanchang University, No.17, Yongwai Zheng Street, Donghu District, Nanchang, 330000, Jiangxi, China

\section{Jianfang Rong}

Department of Gastroenterology, The First Affiliated Hospital of Nanchang University, No.17, Yongwai Zheng Street, Donghu District, Nanchang, 330000, Jiangxi, China

\section{Fangfei Wang}

Department of Gastroenterology, The First Affiliated Hospital of Nanchang University, No.17, Yongwai Zheng Street, Donghu District, Nanchang, 330000, Jiangxi, China

\section{Lili Yan}

Laboratory of Biochemistry and Molecular Biology, Jiangxi Institute of Medical Sciences, Nanchang 330000, Jiangxi Province, China

\section{Yanping Song}

Department of Gastroenterology, The First Affiliated Hospital of Nanchang University, No.17, Yongwai Zheng Street, Donghu District, Nanchang, 330000, Jiangxi, China

\section{Yong Xie ( $\nabla$ xieyong_tfahoncu@163.com )}

First Affiliated Hospital of Nanchang University https://orcid.org/0000-0002-5290-5579

\section{Research}

Keywords: IGFBP7, prognosis, immune infiltration, gastric cancer, bioinformatics analysis 
Posted Date: June 9th, 2020

DOl: https://doi.org/10.21203/rs.3.rs-33369/v1

License: (c) (i) This work is licensed under a Creative Commons Attribution 4.0 International License. Read Full License 


\section{Abstract}

Background Insulin-like growth factor binding protein-7 (IGFBP7) contributes to multiple biological processes in various tumors. However, the role of IGFBP7 in gastric cancer (GC) is still undetermined. The study aims to explore the role of IGFBP7 in GC via an integrated bioinformatics analysis.

Methods IGFBP7 expression levels in GC and its normal gastric tissues were analyzed using multiple databases, including the Tumor Immune Estimation Resource (TIMER), Oncomine, The Cancer Genome Atlas (TCGA) and Gene Expression Omnibus (GEO) databases. The methylation analysis was conducted with MEXPRESS, UALCAN and Xena online tools. The survival analysis was conducted using the KaplanMeier Plotter and Gene Expression Profiling Interactive Analysis (GEPIA) databases. Coexpressed genes of IGFBP7 were selected with the cBioPortal tool and enrichment analysis was conducted with the clusterProfiler package in R software. Gene set enrichment analysis (GSEA) was performed to explore the IGFBP7-related biological processes involved in GC. Correlations between IGFBP7 and immune cell infiltrates were analyzed using the TIMER database.

Results IGFBP7 expression was significantly upregulated in GC and correlated with stage, grade, tumor status and Helicobacter pylori infection. High IGFBP7 expression and low IGFBP7 methylation levels were significantly associated with short survival of patients with GC. Univariate and multivariate analyses revealed that IGFBP7 was an independent risk factor for GC. The coexpressed genes LHFPL6, SEPTIN4, HSPB2, LAYN and GGT5 predicted unfavorable outcomes of GC. Enrichment analysis showed that the coexpressed genes were involved in extracellular matrix (ECM)-related processes. GSEA indicated that IGFBP7 was positively related to ECM and inflammation-related pathways. TIMER analysis indicated that the IGFBP7 expression level was strongly correlated with genes related to various infiltrating immune cells in GC, especially with gene markers of tumor associated macrophages (TAMs).

Conclusions We demonstrate that increased IGFBP7 expression correlates with poor prognosis and immune cell infiltration in GC. IGFBP7 might be a potential biomarker for the diagnosis and targeted therapy for GC.

\section{Background}

Gastric cancer (GC) remains an important malignant tumor with more than one million new cases and 783,000 deaths globally in 2018 [1]. Helicobacter pylori (H. pylori) is the major risk factor for GC and causes chronic gastric inflammation and actives cancer-related signaling pathways [2]. In the past few decades, as significant progress has been made in the early diagnosis and treatment of GC, and H. pylori infection has been effectively eradicated on a large scale, the incidence and mortality of GC have dropped considerably $[3,4]$. However, the prognosis of GC remains poor. Aberrantly expressed genes in GC may participate in tumorgenesis and cancer progression, which are related to unfavorable outcomes of GC. Therefore, identification of new potential biomarkers for the diagnosis and targeted therapy of GC is urgently needed. 
Insulin-like growth factor (IGF) is well known to be involved in cell growth and regulated by a group of IGF binding proteins (IGFBPs) and their receptors [5]. Insulin-like growth factor binding protein-7 (IGFBP7) is a secreted protein that binds to the IGF-I receptor with low affinity and blocks insulin action [6, 7]. IGFBP7 acts as an IGF-dependent and IGF-independent cell growth regulator. Its IGF-independent actions seem to contribute to tumor cell growth, angiogenesis, epithelial mesenchymal transition (EMT) and cell apoptosis [8-13]. The expression level of IGFBP7 is regulated by DNA methylation in various cancer types [14-17]. IGFBP7 is assumed to be a growth suppressing gene in some tumors, because reduced expression has often been found in these tumors, such as in colorectal cancer, hepatocellular cancer, and thyroid cancer [18-21]. However, it has been reported that IGFBP7 levels in serum in the esophageal squarmous cell cancer are significantly higher than those in normal tissues and might be a potential biomarker for diagnosis [22]. Another study utilizing mass spectrometry-based proteomics methods revealed that IGFBP7 was overexpressed in head and neck squamous cell carcinomas, which was associated with inferior survival and an increased risk of disease progression [23].

In gastric cancer, the role of IGFBP7 is undetermined [24, 25]. Therefore, studission, and epigenetic regulation and its correlation with clinical outcome in GC patients using multiple es with substantial sample sizes and utilizing omics-technologies are needed to confirm the role of IGFBP7 in GC. In this study, we performed a comprehensive analysis of IGFBP7 expreavailable databases. To investigate the possible pathogenic mechanism of IGFBP7 in GC, we further performed enrichment analysis of coexpressed genes and gene set enrichment analysis (GSEA) of IGFBP7. Finally, the relationship between IGFBP7 and immune cell infiltration was also explored. Our work highlights the important role of IGFBP7 on the carcinogenicity and prognosis in GC and indicates that IGFBP7 could act as a potential therapeutic target for GC.

\section{Materials And Methods}

\section{Expression analyses of IGFBP7}

Tumor Immune Estimation Resource (TIMER, https://cistrome.shinyapps.io/timer/) is a comprehensive tool for analyzing immune infiltrates according to diverse cancer types [26], and was first used to analyze the mRNA levels of IGFBP7 in 33 cancers based on TCGA expression profile data. The Oncomine database (https://www.oncomine.org/resource/login.html) is an accessible online cancer microarray database that was further used to explore the mRNA expression levels of IGFBP7 in different subtypes of GC with log2-transformed expression data. The filter thresholds used in the Oncomine database analysis were defined as follows: $P$-value $<1 \mathrm{E}-4$, fold change $>2$ and gene rank in the top $10 \%$.

The expression and phenotype data of the TCGA-STAD dataset were obtained from the GDC Hub of UCSC Cancer Genome Browser (http://xena.ucsc.edu/). For gene expression, HTSeq-count data were retrieved. The expression profiles of GSE54129, GSE15459, GSE79973 and GSE118916 were downloaded from the Gene Expression Omnibus (GEO) database (https://www.ncbi.nlm.nih.gov/geo/) and were listed in Table S1. The expression matrix was log2 transformed in R (version 3.6.1) if necessary. 


\section{Methylation analyses of IGFBP7}

The MEXPRESS tool (https://mexpress.be/index.html) was used to visualize the expression, methylation and clinical data from TCGA $[27,28]$, which was used to visualize the mRNA expression and methylation of IGFBP7 in GC. Promoter methylation levels of IGFBP7 in GC and its normal gastric tissues were analyzed in UALCAN online tool (http://ualcan.path.uab.edu/cgi-bin/ualcan-res.pl). The overall survival analysis of IGFBP7 methylation was conducted in UCSC Cancer Genome Browser (http://xena.ucsc.edu/).

\section{Survival analyses of IGFBP7}

The Kaplan-Meier Plotter tool (https://kmplot.com/analysis/) was used to assess the effect of IGFBP7 expression on survival in GC with microarray data from the GEO database. The query probe ID 213910_at was examined. A total of $875 \mathrm{GC}$ samples, $640 \mathrm{GC}$ samples and $498 \mathrm{GC}$ samples were used to analyze the correlation between IGFBP7 expression and overall survival (OS), first progression survival (FPS) and post progression survival (PPS), respectively. In addition, Gene Expression Profiling and Interactive Analysis (GEPIA, http://gepia.cancer-pku.cn/detail.php) was further used to verify the survival analysis based on RNA-seq data from the TCGA database. The median expression value of IGFBP7 was used to divide GC samples into high and low groups. The log-rank method was used for the hypothesis test. A $P$ value $<0.05$ was considered statistically significant.

\section{Analyses of genes coexpressed with IGFBP7}

First, the top eight coexpressed genes of IGFBP7 according to adjusted P values were selected, and correlation analysis was performed in the cBioPortal online database (https://www.cbioportal.org/). Second, survival analysis of the eight genes was conducted using the GEPIA online tool. Finally, the top 200 coexpressed genes of IGFBP7 were selected, and enrichment analysis was performed with the clusterProfiler package in $\mathrm{R}$ (version 3.6.1).

\section{Gene set enrichment analysis (GSEA)}

To explore the potential pathogenic biological processes of IGFBP7, we conducted GSEA for TCGA-STAD data using GSEA v4.3.0 software. The gene set c2.cp.kegg.v7.1.symbols.gmt was selected for further analysis. The number of permutations was 1000. NES (normalized enrichment score) $>1$ and FDR FDR (false discovery rate) $\mathrm{q}-\mathrm{val}<0.05$ were set as cut-offs for significant enrichment.

\section{Immune infiltration analysis}


Correlations between IGFBP7 expression and various infiltrating immune cell types were investigated using the TIMER database. Additionally, correlations between IGFBP7 expression and gene markers of infiltrating immune cell types were also explored.

\section{Statistical analyses}

Scatter plots were generated using GraphPad Prism 7.0. SPSS 21.0 software was used to conduct statistical analyses. A standard Student's t-test, paired t-test or Mann-Whitney U-test was used to compare the difference within two groups. ANOVA analysis or Kruuskal-Wallis test was used to compare difference among more than two groups. Univariate and multivariate Cox regression analyses were conducted in $\mathrm{R}$. $P$-value $<0.05$ was considered statistically significant.

\section{Results}

\section{Transcriptional and methylation levels of IGFBP7 in patients with GC}

To determine the expression levels of IGFBP7 in different cancers, we analyzed IGFBP7 expression among various cancers using the TIMER database. The results revealed that the expression levels of IGFBP7 were divergent in different cancers. In stomach adenocarcinoma (STAD), the expression of IGFBP7 was significantly increased compared to that in normal tissues (Fig. 1A). Oncomine database further revealed that IGFBP7 mRNA expression was upregulated in GC among seven datasets (Fig. 1B). Moreover, increased IGFBP7 expression in GC was confirmed using TCGA (Fig. 1C) and three GEO datasets (Fig. 1D-F). In addition, the mRNA expression of IGFBP7 was significantly upregulated in gastric diffuse adenocarcinoma, intestinal type adenocarcinoma, and mixed adenocarcinoma compared to normal gastric tissues (Table 1). Taken together, the results of multiple datasets suggested that the mRNA expression of IGFBP7 was significantly upregulated in GC tissues compared to normal gastric tissues. 
Table 1

The mRNA expression of IGFBP7 was upregulated in different types of gastric cancer compared with normal gastric tissues.

\begin{tabular}{|lllll|}
\hline Different types of GC vs. Normal & Fold Change & t-test & P-value & reference \\
\hline Diffuse Gastric Adenocarcinoma & 4.217 & 14.986 & $6.31 \mathrm{E}-13$ & Chen Gastric \\
\hline Gastric Instinal type Adenocarcinoma & 2.333 & 11.245 & $6.19 \mathrm{E}-19$ & Chen Gastric \\
\hline Gastric Mixed Adenocarcinoma & 4.414 & 8.377 & $1.24 \mathrm{E}-05$ & Chen Gastric \\
\hline Gastric Instinal type Adenocarcinoma & 2.721 & 7.102 & $3.26 \mathrm{E}-09$ & DErrico Gastric \\
\hline Gastric Mixed Adenocarcinoma & 4.669 & 7.154 & $1.54 \mathrm{E}-06$ & DErrico Gastric \\
\hline Diffuse Gastric Adenocarcinoma & 2.238 & 4.998 & $4.16 \mathrm{E}-06$ & Cho Gastric \\
\hline Gastric Adenocarcinoma & 2.139 & 2.529 & $3.50 \mathrm{E}-02$ & Cho Gastric \\
\hline Gastric Instinal type Adenocarcinoma & 1.987 & 3.061 & $3.00 \mathrm{E}-03$ & Cho Gastric \\
\hline
\end{tabular}

To examine whether the mRNA expression of IGFBP7 was regulated by DNA methylation, we used the MEXPRESS tool to visualize the gene expression and methylation levels of IGFBP7. The results revealed that all probes in the promoter region showed a significantly negative correlation with IGFBP7 mRNA levels (Figure S1A). In addition, the promoter methylation level of IGFBP7 was reduced in GC compared to that in normal gastric tissue (Figure S1B), and promoter hypomethylation was associated with a poor prognosis of GC (Figure S1C). Altogether, the results showed that the expression of IGFBP7 was negatively regulated by methylation and was associated with prognosis of GC.

\section{Relationship between IGFBP7 and clinicopathological characteristics of GC patients}

To explore the relationship between the mRNA expression of IGFBP7 and the clinicopathological characteristics of GC patients, we analyzed clinical information of GC samples from the TCGA-STAD project. The results revealed that the mRNA expression of IGFBP7 was significantly increased in the G3 phase $(P<0.001$, Fig. 2C), advanced tumor status (T2/3/4) $(P<0.001$. Figure 2D) and advanced stages (II/III/IV) $(P<0.05$, Fig. 2G). The correlation between IGFBP7 expression and stage was also confirmed using the GSE15459 dataset $(P<0.01$, Fig. $2 \mathrm{H})$. The expression level of IGFBP7 was significantly higher in GC samples with $H$. pylori infection than that in $\mathrm{GC}$ samples without $H$. pylori infection $(P=0.001$, Fig. 2I). However, the mRNA expression of IGFBP7 showed no significant correlation with age, gender, node status and metastasis status ( $P>0.05$, Fig. $2 \mathrm{~A}, \mathrm{~B}, \mathrm{E}, \mathrm{F})$.

\section{High IGFBP7 expression predicted a poor prognosis in GC patients}


To explore the prognostic value of IGFBP7 in GC patients, we used GC sample data based on microarray chip and transcriptome sequencing from two different databases. The microarray chip results revealed that high IGFBP7 expression was strongly associated with poor overall survival (OS, Fig. 3A), first progression survival (FP, Fig. 3B) and post progression survival (PPS, Fig. 3C) of GC. Furthermore, the analysis based on transcriptome sequencing data indicated that high IGFBP7 expression was significantly related to poor overall survival (Fig. 3D) and disease-free survival (Fig. 3E). In addition, univariate and multivariate Cox regression analyses revealed that high IGFBP7 expression was an independent risk factor for unfavorable survival of GC (Table 2). 
Table 2

Univariate and multivariate analysis of IGFBP7 mRNA levels and clinical parameters in TCGA gastric cancer patients

\begin{tabular}{|c|c|c|c|c|c|c|}
\hline \multirow[t]{2}{*}{ Variables } & \multicolumn{3}{|c|}{ Univariate analysis } & \multicolumn{3}{|c|}{ Multivariate analysis } \\
\hline & $\mathrm{HR}$ & $95 \% \mathrm{Cl}$ & $P$ value & $\mathrm{HR}$ & $95 \% \mathrm{Cl}$ & $P$ value \\
\hline Age(years) & 1.68 & $1.13-2.49$ & $0.010 * *$ & 1.75 & $1.18-2.59$ & $0.006^{* \star}$ \\
\hline \multicolumn{7}{|l|}{$>60$} \\
\hline \multicolumn{7}{|l|}{$\leq 60$} \\
\hline Gender & 1.47 & $1-2.15$ & $0.049 *$ & 1.44 & $0.98-2.11$ & 0.06 \\
\hline \multicolumn{7}{|l|}{ Male } \\
\hline \multicolumn{7}{|l|}{ Female } \\
\hline Stage & 1.72 & $1.19-2.48$ & $0.004^{\star \star}$ & 1.48 & $0.90-2.43$ & 0.12 \\
\hline \multicolumn{7}{|l|}{$I I I+I V$} \\
\hline \multicolumn{7}{|l|}{$|+| \mid$} \\
\hline Grade & 1.28 & $0.089-1.85$ & 0.186 & NA & NA & NA \\
\hline \multicolumn{7}{|l|}{ G3 } \\
\hline \multicolumn{7}{|l|}{$\mathrm{G} 1+\mathrm{G} 2$} \\
\hline T stage & 1.46 & $0.94-2.26$ & 0.096 & NA & NA & NA \\
\hline \multicolumn{7}{|l|}{$\mathrm{T} 3+\mathrm{T} 4$} \\
\hline \multicolumn{7}{|l|}{$\mathrm{T} 1+\mathrm{T} 2$} \\
\hline $\mathrm{N}$ stage & 1.70 & $1.11-2.61$ & $0.014^{\star}$ & 1.29 & $0.72-2.87$ & 0.39 \\
\hline \multicolumn{7}{|l|}{ N1 N3 } \\
\hline \multicolumn{7}{|l|}{ NO } \\
\hline M stage & 1.63 & $0.85-3.11$ & 0.141 & NA & NA & NA \\
\hline \multicolumn{7}{|l|}{ M1 } \\
\hline \multicolumn{7}{|l|}{ MO } \\
\hline IGFBP7 & 1.5 & $1-2.1$ & $0.032^{\star}$ & 1.51 & $1.06-2.15$ & $0.022^{\star}$ \\
\hline \multicolumn{7}{|l|}{ High } \\
\hline \multicolumn{7}{|l|}{ Low } \\
\hline *, $P<0.05$; * & $P<0$ & & & & & \\
\hline
\end{tabular}




\section{Analyses of genes coexpressed with IGFBP7 in GC}

Coexpressed genes typically have similar functions. The top eight coexpressed genes of IGFBP7 arranged by adjusted $\mathrm{P}$ values were identified. The correlation analysis revealed that IGFBP7 was highly positively correlated with tetraspanin subfamily member 6(LHFPL6), matrix Gla protein (MGP), septin 4(SEPTIN4), heat shock protein family B (Small) member 2(HSPB2), actin alpha 2, smooth muscle (ACTA2), layilin (LAYN),necdin, MAGE family member (NDN) and gamma-glutamyltransferase 5 (GGT5) (Fig. 4A-H). The survival map indicated that all 8 genes were risk factors for unfavorable survival of GC, among which five genes showed statistically significant relationships with survival (Fig. 4I). Overall survival analysis further confirmed that high expression levels of LHFPL6, SEPTIN4, HSPB2, LAYN and GGT5 were associated with poor prognosis of GC (Fig. 4J-N).

To explore the potential biological function of genes coexpressed with IGFBP7, top 200 genes were selected to conduct the enrichment analysis. The GO biological process (BP) analysis showed that the terms extracellular structure organization, extracellular matrix organization, muscle system process, ameboidal-type cell migration and regulation of cellular response to growth factor stimulus were significantly enriched (Figure S2A). The GO term cellular component (CC) analysis showed that the terms collagen-containing extracellular matrix, contractile fiber and extracellular matrix component were significantly enriched (Figure S2B). The molecular function (MF) analysis showed that the terms extracellular matrix structural constituent, glycosaminoglycan binding and collagen binding were mainly enriched (Figure S2C). KEGG pathway analysis showed that vascular smooth muscle contraction was significantly enriched (Figure S2D). Overall, the enrichment analysis indicated that IGFBP7 and its coexpressed genes may be involved in extracellular matrix- related signaling processes.

\section{GSEA identified IGFBP7-related pathways}

To analyze the possible biological pathways regulated by IGFBP7 in GC, we conducted GSEA between high and low IGFBP7 expression groups based on the TCGA-STAD dataset. A total of 22 pathways were significantly enriched in the IGFBP7 high expression phenotype (listed in Table S2). The main results showed that the terms cytokine-cytokine receptor interaction (Fig. 5A); calcium signaling pathway (Fig. 5B); vascular smooth muscle contraction (Fig. 5C); cell adhesion related terms such as ECM receptor interaction(Fig. 5D), cell adhesion molecules cams (Fig. 5E) and focal adhesion (Fig. 5F); and immune cell-related terms such as hematopoietic cell lineage(Fig. 5G), complement coagulation cascades(Fig. $5 \mathrm{H}$ ) and leukocyte transendothelial migration(Fig. 5I) were significantly enriched. Other enriched terms, such as Hedgehog signaling pathway, gap junction, regulation of actin cytoskeleton, MAPK signaling pathway, JAK-STAT signaling pathway are listed in Table S2.

\section{IGFBP7 expression correlated with the infiltration levels of immune cells in GC}


As the enrichment analysis above indicated that cytokine-cytokine receptor interactions and immune cell related pathways were noticeably enriched, we wondered that whether immune cell infiltration was involved in the pathogenic role of IGFBP7 in GC. Therefore, we explored the relationship between IGFBP7 expression and infiltrating immune cells in GC using the TIMER database. The results showed that high IGFBP7 expression had the most significant correlation with macrophages (Cor $=0.696, P=6.97 \mathrm{e}-55$ ), followed by dendritic cells (Cor $=0.494, P=3.43 \mathrm{e}-24), \mathrm{CD} 4+\mathrm{T}$ cells $(\mathrm{Cor}=0.433, P=3.66 \mathrm{e}-18), \mathrm{CD} 8+\mathrm{T}$ cells (Cor $=0.312, P=8.37 \mathrm{e}-10$ ) and neutrophils (Cor $=0.301, P=3.50 \mathrm{e}-09)$ (Fig. 6). In addition, we also analyzed the correlations between IGFBP7 expression and immune markers of tumor associated macrophages (TAMs), M1 macrophages, dendritic cells, T cells and neutrophils. The results revealed that IGFBP7 expression had a strong correlation with gene markers of TAMs, DCs, Tregs, Th1, Th2 cells and neutrophils (Table 3). However, the expression of NOS2, IRF5, PTGS2 and CD68 in M1 macrophages showed a relatively weak correlation with IGFBP7 expression (Table 3). Overall, the results demonstrated that IGFBP7 had a strong relationship with immune cell infiltration in GC. 
Table 3

Correlation analysis between IGFBP7 mRNA expression and gene markers of immune cells in gastric cancer

\begin{tabular}{|c|c|c|c|}
\hline Immune cells & Gene marker & Correlation coefficient & $P$ value \\
\hline \multirow[t]{7}{*}{ TAM(M2) } & CCL2 & 0.597 & 0 \\
\hline & IL10 & 0.402 & $1.53 \mathrm{E}-17$ \\
\hline & CD206 & 0.392 & 0 \\
\hline & CD163 & 0.41 & $4.52 \mathrm{E}-35$ \\
\hline & VSIG4 & 0.488 & $5.44 \mathrm{E}-51$ \\
\hline & CSF1R & 0.564 & 0 \\
\hline & FCGR2A & 0.453 & 0 \\
\hline \multirow[t]{4}{*}{ M1 } & NOS2 & -0.067 & 1.73E-01 \\
\hline & IRF5 & 0.255 & $1.54 \mathrm{E}-07$ \\
\hline & PTGS2 & 0.191 & 8.93E-05 \\
\hline & CD68 & 0.238 & $1.06 \mathrm{E}-06$ \\
\hline \multirow[t]{4}{*}{ DCs } & ITGAX & 0.4 & 0 \\
\hline & CD1C & 0.511 & 5.88E-29 \\
\hline & NRP1 & 0.661 & 0 \\
\hline & THBD & 0.587 & $9.92 \mathrm{E}-40$ \\
\hline \multirow[t]{3}{*}{ Treg } & FOXP3 & 0.345 & $6.91 \mathrm{E}-13$ \\
\hline & STAT5B & 0.455 & 0 \\
\hline & TGFB1 & 0.611 & 8.77E-44 \\
\hline \multirow[t]{4}{*}{ Th1 } & STAT4 & 0.358 & 6.97E-14 \\
\hline & TBX21 & 0.303 & 3.07E-10 \\
\hline & CD4 & 0.494 & 0 \\
\hline & TNF & 0.101 & 3.98E-02 \\
\hline \multirow[t]{4}{*}{ Th2 } & GATA3 & 0.427 & 0 \\
\hline & CXCR4 & 0.504 & 4.58E-28 \\
\hline & CCR8 & 0.39 & $1.45 \mathrm{E}-16$ \\
\hline & STAT5A & 0.336 & $1.93 \mathrm{E}-12$ \\
\hline
\end{tabular}




\begin{tabular}{|llll|}
\hline Immune cells & Gene marker & Correlation coefficient & $P$ value \\
\hline Neutrophils & MPO & 0.355 & $8.92 \mathrm{E}-14$ \\
& ITGAM & 0.449 & 0 \\
& CCR7 & 0.438 & 0 \\
\hline & CD16(FCGR3A) & 0.372 & $4.81 \mathrm{E}-15$ \\
\hline & CD32(FCG2A) & 0.453 & 0 \\
\hline
\end{tabular}

\section{Discussion}

The current findings reveal that the mRNA expression of IGFBP7 is divergent in different cancers, which suggests that IGFBP7 functions as both an oncogene or tumor suppressor according to the cancer types. Using large transcriptome sequencing data, we demonstrated that IGFBP7 mRNA was overexpressed in GC specimens and correlated with stage, grade, tumor status and H. pylori infection. Furthermore, we found that a high IGFBP7 expression level was significantly associated with poor survival in GC, and served as an independent risk factor for GC. A previous study based on immunohistochemical staining and mRNA revealed that IGFBP7 was positively correlated with invasion, lymph node metastasis and worse survival in GC [25]. Another study based on a high-content antibody microarray found that IGFBP7 exhibited the most profound variation ( $\log 2 \mathrm{FC}=2.04$, adj. $p$-vaule $<0.05$ ) between 16 pairs of gastric adenocarcinomas and adjacent tissues and may be a candidate marker for the diagnosis of GC [29] Altogether, these results suggest that IGFBP7 may contribute to the carcinogenic process in GC and serve as a potential prognostic marker.

Increasing evidence has reported that IGFBP7 expression is regulated by epigenetic changes, especially by DNA methylation in various cancers [16, 30-33]. In this study, we found a significantly negative correlation between the expression of IGFBP7 and methylation levels in GC. IGFBP7 methylation levels were decreased in GC compared with normal tissues, and hypomethylation of IGFBP7 was associated with unfavorable survival of GC. Intriguingly, a study from Kim et al revealed that IGFBP7 expression was silenced by aberrant methylation in GC cells and GC tissues [34]. The difference in the results may be due to different detection methods and sample sizes, as well as the different expression types of IGFBP7 in GC. Importantly, the current study was a comprehensive bioinformatics analysis based on multiple databases and large numbers of GC samples. In addition, IGFBP7 has been identified as a novel tumor stroma marker that expressed in activated tumor-associated fibroblasts (CAFs) in several epithelial tumor types [35]. As activated CAFs in carcinomas play an important role in tumor cell growth, invasion and metastasis, contrasting expression of IGFBP7 in tumor microenvironment (TME) cells may account for the divergent results in different studies.

Coexpressed genes usually have similar functions. The coexpression analysis indicated that IGFBP7 was highly positively correlated with the top eight coexpressed genes (LHFPL6, MGP, SEPTIN4, HSPB2, ACTA2, LAYN, NDN, and GGT5), and all these genes served as risk factors for unfavorable survival of GC. 
Some of these genes have been reported to promote tumor progression and poor prognosis in malignancy [36-39]. It seems that IGFBP7 and its coexpressed genes may act as good prognosis markers for GC. To explore the potential biological processes of IGFBP7, we conducted GO and KEGG analyses of the coexpressed genes and GSEA analysis for IGFBP7. The enrichment analysis of the top 200 coexpressed genes showed that extracellular matrix (ECM) related processes were significantly enriched. The GSEA revealed that the terms cytokine-cytokine receptor interaction, ECM-related, adhesion receptor interaction, cell adhesion molecules cams, focal adhesion, and immune cell related pathways were significantly enriched in IGFBP7 high expression phenotype. It has been reported that ECM components such as collagen, fibroblasts and their associated signaling molecules contribute to tumor cell proliferation, migration and invasion in various cancers [40, 41]. Moreover, IGFBP7 has been reported to regulate epithelial-mesenchylmal transition (EMT) in some solid tumors $[12,42,43]$. The above results suggest that IGFBP7 and its coexpressed genes may be involved in ECM-related pathways, which would contribute to the utility of IGFBP7 to predict poor prognosis of GC. H. pylori infection is well known to cause chronic gastric inflammation and eventually GC. EMT and the tumor microenvironment contribute to H. pylori induced GC [44]. In this study, we demonstrated that IGFBP7 was highly expressed in GC samples with $H$. pylori infection. As a secret protein, IGFBP7 contributed significantly to immune modulation of mosenchymal stromal cells in experimental colitis and was involved in the modulation of cytokine production by T cells [45]. Therefore, IGFBP7 may be involved in H. pylori related inflammatory response during the progression of GC. Other enriched pathways related to high IGFBP7 expression, such as the Hedgehog signaling pathway, MAPK signaling pathway and JAK-STAT signaling pathway have been widely reported to contribute to the carcinogenic process of GC [46-48]. Hence, IGFBP7 might participate in a variety of biological pathways in the carcinogenic process of GC.

Tumor-infiltrating immune cells are important components of the tumor stroma and contribute to tumor progression and response to cancer therapy[49]. Our results demonstrated that there is a robustly positive relationship between IGFBP7 expression level and infiltration of macrophages, DCs, CD4 + T cells and $\mathrm{CD} 8+\mathrm{T}$ cells, which indicated that IGFBP7 may be involved in regulating tumor immunology in GC. IGFBP7 expression showed a strong correlation with TAM-related gene markers but a weak correlation with M1-related gene markers. TAM infiltration has been reported to be associated with various malignant phenotypes and poor prognosis in GC $[50,51]$. These above results suggested the hypothetical role of IGFBP7 in regulating the TAM phenotype in GC, which plays an important role in gastric carcinogenesis and prognosis. In addition, a relatively strong correlation between IGFBP7 expression and gene markers of DCs, Treg, Th1 and Th2 cells indicated the potential role of IGFBP7 in regulating DCs and T cell function in GC. In response to $H$. pylori infection in the gastric mucosa, various immune cells including macrophages, DCs and Th1 polarized immune cells are activated and recruited to gastric epithelial cells by a variety of bacterial factors [52]. The results indicate that IGFBP7 may play an important role in the immune regulation of $H$. pylorirelated gastric diseases. In fact, some members of the IGFBP superfamily such as IGFBP1, IGFBP2 and IGFBP5 have been reported to be upregulated by $H$. pylori infection [53-55]. Whether IGFBP7 participates in the pathogenesis of $H$. pylori-related diseases requires further experimental verification. 


\section{Conclusion}

In conclusion, we demonstrated that increased IGFBP7 expression correlates with poor prognosis and immune infiltration in GC. Our work highlights the important role of IGFBP7 on the carcinogenicity and prognosis in GC and indicates that IGFBP7 could act as a prognostic biomarker and therapeutic target in GC.

\section{Abbreviations}




\begin{tabular}{|c|c|}
\hline IGFBP7 & Insulin-like growth factor binding protein-7 \\
\hline GC & gastric cancer \\
\hline TIMER & Tumor Immune Estimation Resource \\
\hline TCGA & The Cancer Genome Atlas \\
\hline GEO & Gene Expression Omnibus \\
\hline GEPIA & Gene Expression Profiling Interactive Analysis \\
\hline ECM & Extracellular matrix \\
\hline GSEA & Gene set enrichment analysis \\
\hline H. pylori & Helicobacter pylori \\
\hline IGF & Insulin-like growth factor \\
\hline IGFBPs & IGF binding proteins \\
\hline NES & normalized enrichment score \\
\hline FDR & false discovery rate \\
\hline STAD & stomach adenocarcinoma \\
\hline LHFPL 6 & tetraspanin subfamily member 6 \\
\hline MGP & matrix Gla protein \\
\hline SEPTIN4 & Septin4 \\
\hline HSPB2 & heat shock protein family B (Small) member 2 \\
\hline ACTA2 & actin alpha 2 , smooth muscle \\
\hline$\angle A Y N$ & layilin \\
\hline$N D N$ & necdin, MAGE family member \\
\hline GGT5 & gamma-glutamyltransferase 5 \\
\hline GO & gene ontology \\
\hline BP & biological process \\
\hline $\mathrm{CC}$ & cellular component \\
\hline MF & molecular function \\
\hline TAMs & tumor associated macrophages \\
\hline OS & overall survival \\
\hline FPS & first progression survival \\
\hline
\end{tabular}

Page 16/28 


\section{Declarations}

\section{Acknowledgements}

Not applicable

\section{Authors' contributions}

$\mathrm{XY}$ and ZQY conceived the design of this study. ZQY drafted the manuscripts. ZQY, ZRL, SCH, WH and RJF performed data analysis. WFF, YLL and SYP helped interpret the results and give suggestions. All authors have read and approved the finical manuscript.

\section{Funding}

This work was supported by the National Key Research and Development Program of China (No. 2016YFC1302201), National Natural Science Foundation of China (No. 81970502, No. 81860107, No. 81260076) and Leading Talent Training Plan of the Gan-Po Outstanding Talents 555 Project of Jiangxi Province (2010-3-61).

\section{Availability of data and materials}

The datasets analyzed in the study are available in the following public databases, including GEO (https://www.ncbi.nlm.nih.gov/geo/), TIMER (https://cistrome.shinyapps.io/timer/), Oncomine (https://www.oncomine.org/resource/main.html), UCSC Xena (https://xena.ucsc.edu/), cBioPortal (https://www.cbioportal.org/), MEXPRESS (https://mexpress.be/), Kaplan-Meier Plotter (http://kmplot.com/analysis/index.php?p=service\&cancer=gastric) and GEPIA (http://gepia.cancerpku.cn/detail.php) online tools.

\section{Ethics approval and consent to participate}

Not applicable.

\section{Consent for publication}

Not applicable. 


\section{Competing interests}

All authors declare that they have no competing interests

\section{Conflict of interests}

The authors have no conflict of interest

\section{References}

1. Bray F, Ferlay J, Soerjomataram I, Siegel RL, Torre LA, Jemal A: Global cancer statistics 2018 : GLOBOCAN estimates of incidence and mortality worldwide for 36 cancers in 185 countries. $C A$ Cancer J Clin 2018, 68(6):394-424.

2. Zhang $X Y$, Zhang PY, Aboul-Soud MA: From inflammation to gastric cancer: Role of Helicobacter pylori. Oncol Lett 2017, 13(2):543-548.

3. Choi IJ, Kim CG, Lee JY, Kim YI, Kook MC, Park B, Joo J: Family History of Gastric Cancer and Helicobacter pylori Treatment. N Engl J Med 2020, 382(5):427-436.

4. Fukase K, Kato M, Kikuchi S, Inoue K, Uemura N, Okamoto S, Terao S, Amagai K, Hayashi S, Asaka M: Effect of eradication of Helicobacter pylori on incidence of metachronous gastric carcinoma after endoscopic resection of early gastric cancer: an open-label, randomised controlled trial. Lancet 2008, 372(9636):392-397.

5. Oh Y: IGFBPs and neoplastic models. New concepts for roles of IGFBPs in regulation of cancer cell growth. Endocrine 1997, 7(1):111-113.

6. Oh Y, Nagalla SR, Yamanaka Y, Kim HS, Wilson E, Rosenfeld RG: Synthesis and characterization of insulin-like growth factor-binding protein (IGFBP)-7. Recombinant human mac25 protein specifically binds IGF-I and -II. J Biol Chem 1996, 271(48):30322-30325.

7. Yamanaka Y, Wilson EM, Rosenfeld RG, Oh Y: Inhibition of insulin receptor activation by insulin-like growth factor binding proteins. J Biol Chem 1997, 272(49):30729-30734.

8. Zhao W, Wang J, Zhu B, Duan Y, Chen F, Nian W, Sun J, Zhang B, Tong Z, Chen Z: IGFBP7 functions as a potential lymphangiogenesis inducer in non-small cell lung carcinoma. Oncol Rep 2016, 35(3):1483-1492.

9. Tamura K, Yoshie M, Hashimoto K, Tachikawa E: Inhibitory effect of insulin-like growth factor-binding protein-7 (IGFBP7) on in vitro angiogenesis of vascular endothelial cells in the rat corpus luteum. $J$ Reprod Dev 2014, 60(6):447-453.

10. Zhong Y, Lin Z, Lin X, Lu J, Wang N, Huang S, Wang Y, Zhu Y, Shen Y, Jiang J et al: IGFBP7 contributes to epithelial-mesenchymal transition of HPAEpiC cells in response to radiation. $J$ Cell Biochem 2019, 120(8):12500-12507. 
11. Wang X, Li Y, Zhao Z, Meng Y, Bian J, Bao R, Zhu K, Yang T: IGFBP7 regulates sepsis-induced epithelial-mesenchymal transition through ERK1/2 signaling. Acta Biochim Biophys Sin (Shanghai) 2019, 51(8):799-806.

12. Li Y, Xi Y, Zhu G, Jia J, Huang H, Liu Y, Guo Y, Liu L: Downregulated IGFBP7 facilitates liver metastasis by modulating epithelial-mesenchymal transition in colon cancer. Oncol Rep 2019, 42(5):1935-1945.

13. Cai X, Wang L, Wang X, Hou F: Silence of IGFBP7 suppresses apoptosis and epithelial mesenchymal transformation of high glucose induced-podocytes. Exp Ther Med 2018, 16(2):1095-1102.

14. Komatsu S, Okazaki Y, Tateno M, Kawai J, Konno H, Kusakabe M, Yoshiki A, Muramatsu M, Held WA, Hayashizaki Y: Methylation and downregulated expression of mac25/insulin-like growth factor binding protein-7 is associated with liver tumorigenesis in SV40T/t antigen transgenic mice, screened by restriction landmark genomic scanning for methylation (RLGS-M). Biochem Biophys Res Commun 2000, 267(1):109-117.

15. Ye F, Chen Y, Knösel T, Schlüns K, Pacyna-Gengelbach M, Deutschmann N, Lai M, Petersen I: Decreased expression of insulin-like growth factor binding protein 7 in human colorectal carcinoma is related to DNA methylation. J Cancer Res Clin Oncol 2007, 133(5):305-314.

16. Suzuki M, Shiraishi K, Eguchi A, Ikeda K, Mori T, Yoshimoto K, Ohba Y, Yamada T, Ito T, Baba Y et al: Aberrant methylation of LINE-1, SLIT2, MAL and IGFBP7 in non-small cell lung cancer. Oncol Rep 2013, 29(4):1308-1314.

17. Wilting SM, van Boerdonk RA, Henken FE, Meijer CJ, Diosdado B, Meijer GA, le Sage C, Agami R, Snijders PJ, Steenbergen RD: Methylation-mediated silencing and tumour suppressive function of hsa-miR-124 in cervical cancer. Mol Cancer 2010, 9:167.

18. Ruan WJ, Lin J, Xu EP, Xu FY, Ma Y, Deng H, Huang Q, Lv BJ, Hu H, Cui J et al: IGFBP7 plays a potential tumor suppressor role against colorectal carcinogenesis with its expression associated with DNA hypomethylation of exon 1. J Zhejiang Univ Sci B 2006, 7(11):929-932.

19. Ruan W, Xu E, Xu F, Ma Y, Deng H, Huang Q, Lv B, Hu H, Lin J, Cui J et al: IGFBP7 plays a potential tumor suppressor role in colorectal carcinogenesis. Cancer Biol Ther 2007, 6(3):354-359.

20. Chen D, Yoo BK, Santhekadur PK, Gredler R, Bhutia SK, Das SK, Fuller C, Su ZZ, Fisher PB, Sarkar D: Insulin-like growth factor-binding protein-7 functions as a potential tumor suppressor in hepatocellular carcinoma. Clin Cancer Res 2011, 17(21):6693-6701.

21. Zhang L, Lian R, Zhao J, Feng X, Ye R, Pan L, Wu J, Li M, Huang Y, Cai J: Correction to: IGFBP7 inhibits cell proliferation by suppressing AKT activity and cell cycle progression in thyroid carcinoma. Cell Biosci 2019, 9:57.

22. Huang X, Hong C, Peng Y, Yang S, Huang L, Liu C, Chen L, Chu L, Xu L, Xu Y: The Diagnostic Value of Serum IGFBP7 in Patients with Esophageal Squamous Cell Carcinoma. J Cancer 2019, 10(12):26872693.

23. Sepiashvili L, Hui A, Ignatchenko V, Shi W, Su S, Xu W, Huang SH, O'Sullivan B, Waldron J, Irish JC et al: Potentially novel candidate biomarkers for head and neck squamous cell carcinoma identified 
using an integrated cell line-based discovery strategy. Mol Cell Proteomics 2012, 11(11):1404-1415.

24. Liu L, Yang Z, Zhang W, Yan B, Gu Q, Jiao J, Yue X: Decreased expression of IGFBP7 was a poor prognosis predictor for gastric cancer patients. Tumour Biol 2014, 35(9):8875-8881.

25. Sato Y, Inokuchi M, Takagi Y, Otsuki S, Fujimori Y, Yanaka Y, Kobayashi K, Higuchi K, Kojima K, Kawano T: Relationship between expression of IGFBP7 and clinicopathological variables in gastric cancer. J Clin Pathol 2015, 68(10):795-801.

26. Li T, Fan J, Wang B, Traugh N, Chen Q, Liu JS, Li B, Liu XS: TIMER: A Web Server for Comprehensive Analysis of Tumor-Infiltrating Immune Cells. Cancer Res 2017, 77(21):e108-e110.

27. Koch A, Jeschke J, Van Criekinge W, van Engeland M, De Meyer T: MEXPRESS update 2019. Nucleic Acids Res 2019, 47(W1):W561-w565.

28. Koch A, De Meyer T, Jeschke J, Van Criekinge W: MEXPRESS: visualizing expression, DNA methylation and clinical TCGA data. BMC Genomics 2015, 16:636.

29. Sill M, Schröder C, Shen Y, Marzoq A, Komel R, Hoheisel JD, Nienhüser H, Schmidt T, Kastelic D: Protein Profiling Gastric Cancer and Neighboring Control Tissues Using High-Content Antibody Microarrays. Microarrays (Basel) 2016, 5(3).

30. Sugai T, Yoshida M, Eizuka M, Uesugii N, Habano W, Otsuka K, Sasaki A, Yamamoto E, Matsumoto T, Suzuki $\mathrm{H}$ : Analysis of the DNA methylation level of cancer-related genes in colorectal cancer and the surrounding normal mucosa. Clin Epigenetics 2017, 9:55.

31. Kaya Z, Akkiprik M, Karabulut S, Peker I, Gullu Amuran G, Ozmen T, Gulluoglu BM, Kaya H, Ozer A: Comparison of telomere length and insulin-like growth factor-binding protein 7 promoter methylation between breast cancer tissues and adjacent normal tissues in Turkish women. J Clin Lab Anal 2017, 31(5).

32. Smith E, Ruszkiewicz AR, Jamieson GG, Drew PA: IGFBP7 is associated with poor prognosis in oesophageal adenocarcinoma and is regulated by promoter DNA methylation. Br J Cancer 2014, 110(3):775-782.

33. Li F, Fan YC, Gao S, Sun FK, Yang Y, Wang K: Methylation of serum insulin-like growth factor-binding protein 7 promoter in hepatitis B virus-associated hepatocellular carcinoma. Genes Chromosomes Cancer 2014, 53(1):90-97.

34. Kim J, Kim WH, Byeon SJ, Lee BL, Kim MA: Epigenetic Downregulation and Growth Inhibition of IGFBP7 in Gastric Cancer. Asian Pac J Cancer Prev 2018, 19(3):667-675.

35. Rupp C, Scherzer M, Rudisch A, Unger C, Haslinger C, Schweifer N, Artaker M, Nivarthi H, Moriggl R, Hengstschläger M et al: IGFBP7, a novel tumor stroma marker, with growth-promoting effects in colon cancer through a paracrine tumor-stroma interaction. Oncogene 2015, 34(7):815-825.

36. Wang M, Chen L, Chen Y, Wei R, Guo Q, Zhu S, Guo S, Zhu S, Zhang S, Min L: Intracellular matrix Gla protein promotes tumor progression by activating JAK2/STAT5 signaling in gastric cancer. Mol Oncol 2020, 14(5):1045-1058.

37. Angelis D, Spiliotis ET: Septin Mutations in Human Cancers. Front Cell Dev Biol 2016, 4:122. 
38. Bakthisaran R, Tangirala R, Rao Ch M: Small heat shock proteins: Role in cellular functions and pathology. Biochim Biophys Acta 2015, 1854(4):291-319.

39. Pan JH, Zhou H, Cooper L, Huang JL, Zhu SB, Zhao XX, Ding H, Pan YL, Rong L: LAYN Is a Prognostic Biomarker and Correlated With Immune Infiltrates in Gastric and Colon Cancers. Front Immunol 2019, 10:6.

40. Brassart-Pasco S, Brézillon S, Brassart B, Ramont L, Oudart JB, Monboisse JC: Tumor Microenvironment: Extracellular Matrix Alterations Influence Tumor Progression. Front Oncol 2020, 10:397.

41. Moreira AM, Pereira J, Melo S, Fernandes MS, Carneiro P, Seruca R, Figueiredo J: The Extracellular Matrix: An Accomplice in Gastric Cancer Development and Progression. Cells 2020, 9(2).

42. Wicklein D, Otto B, Suling A, Elies E, Lüers G, Lange T, Feldhaus S, Maar H, Schröder-Schwarz J, Brunner $\mathrm{G}$ et al: CEACAM1 promotes melanoma metastasis and is involved in the regulation of the EMT associated gene network in melanoma cells. Sci Rep 2018, 8(1):11893.

43. Watanabe J, Takiyama Y, Honjyo J, Makino Y, Fujita Y, Tateno M, Haneda M: Role of IGFBP7 in Diabetic Nephropathy: TGF- $\beta 1$ Induces IGFBP7 via Smad2/4 in Human Renal Proximal Tubular Epithelial Cells. PLoS One 2016, 11(3):e0150897.

44. Baj J, Korona-Glowniak I, Forma A, Maani A, Sitarz E, Rahnama-Hezavah M, Radzikowska E, Portincasa P: Mechanisms of the Epithelial-Mesenchymal Transition and Tumor Microenvironment in Helicobacter pylori-Induced Gastric Cancer. Cells 2020, 9(4).

45. Liao Y, Lei J, Liu M, Lin W, Hong D, Tuo Y, Jiang MH, Xia H, Wang M, Huang W et al: Mesenchymal Stromal Cells Mitigate Experimental Colitis via Insulin-like Growth Factor Binding Protein 7-mediated Immunosuppression. Mol Ther 2016, 24(10):1860-1872.

46. Akyala Al, Peppelenbosch MP: Gastric cancer and Hedgehog signaling pathway: emerging new paradigms. Genes Cancer 2018, 9(1-2):1-10.

47. Yang $\mathrm{M}$, Huang CZ: Mitogen-activated protein kinase signaling pathway and invasion and metastasis of gastric cancer. World J Gastroenterol 2015, 21(41):11673-11679.

48. Khanna P, Chua PJ, Bay BH, Baeg GH: The JAK/STAT signaling cascade in gastric carcinoma (Review). Int J Oncol 2015, 47(5):1617-1626.

49. Hanahan D, Coussens LM: Accessories to the crime: functions of cells recruited to the tumor microenvironment. Cancer Cell 2012, 21(3):309-322.

50. Xu J, Yu Y, He X, Niu N, Li X, Zhang R, Hu J, Ma J, Yu X, Sun Y et al: Tumor-associated macrophages induce invasion and poor prognosis in human gastric cancer in a cyclooxygenase-2/MMP9dependent manner. Am J Transl Res 2019, 11(9):6040-6054.

51. Guo J, Yan Y, Yan Y, Guo Q, Zhang M, Zhang J, Goltzman D: Tumor-associated macrophages induce the expression of FOXQ1 to promote epithelial-mesenchymal transition and metastasis in gastric cancer cells. Oncol Rep 2017, 38(4):2003-2010.

52. Wilson KT, Crabtree JE: Immunology of Helicobacter pylori: insights into the failure of the immune response and perspectives on vaccine studies. Gastroenterology 2007, 133(1):288-308. 
53. Luo C, Sun F, Zhu H, Ni Y, Fang J, Liu Y, Shao S, Shen H, Hu J: Insulin-like growth factor binding protein-1 (IGFBP-1) upregulated by Helicobacter pylori and is associated with gastric cancer cells migration. Pathol Res Pract 2017, 213(9):1029-1036.

54. McCaig C, Duval C, Hemers E, Steele I, Pritchard DM, Przemeck S, Dimaline R, Ahmed S, Bodger K, Kerrigan DD et al: The role of matrix metalloproteinase-7 in redefining the gastric microenvironment in response to Helicobacter pylori. Gastroenterology 2006, 130(6):1754-1763.

55. Baricević I, Nedić O, Nikolić JA, Bojić B, Jojić N: Circulating insulin-like growth factors in patients infected with Helicobacter pylori. Clin Biochem 2004, 37(11):997-1001.

\section{Figures}



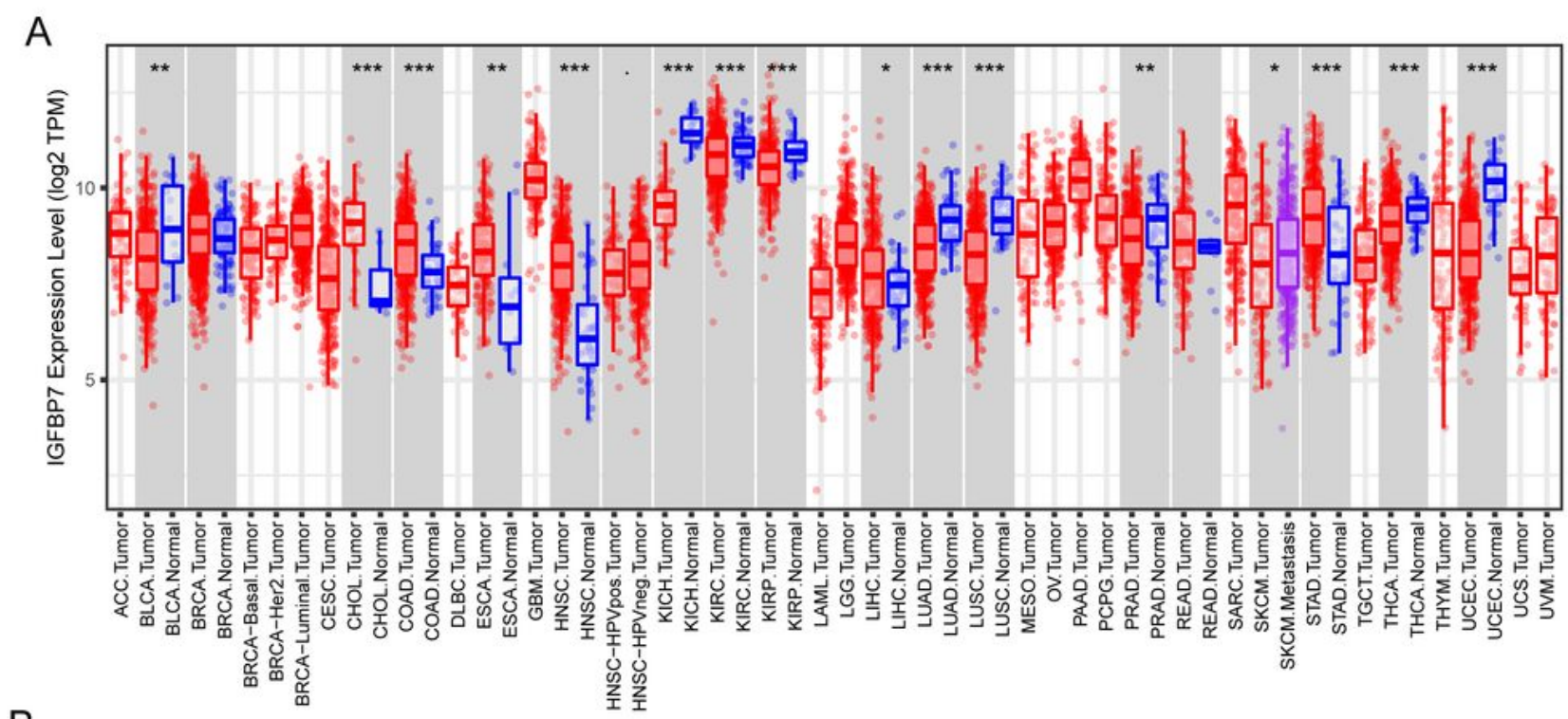

B

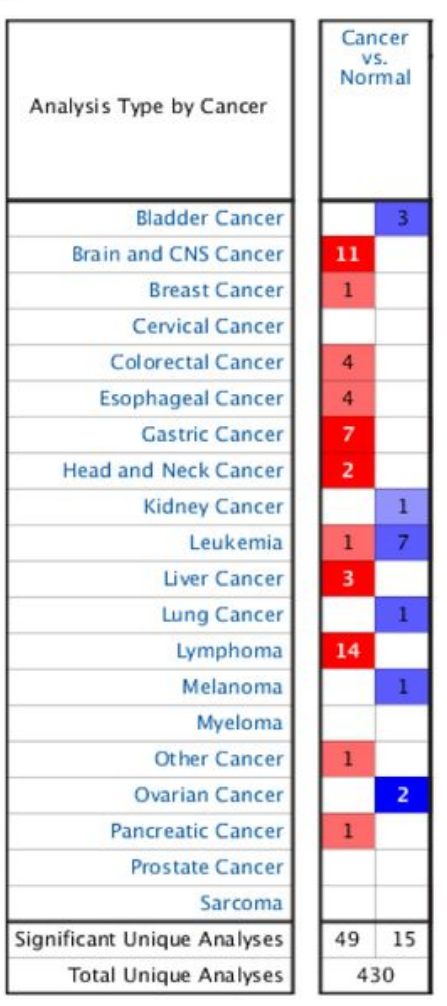

C
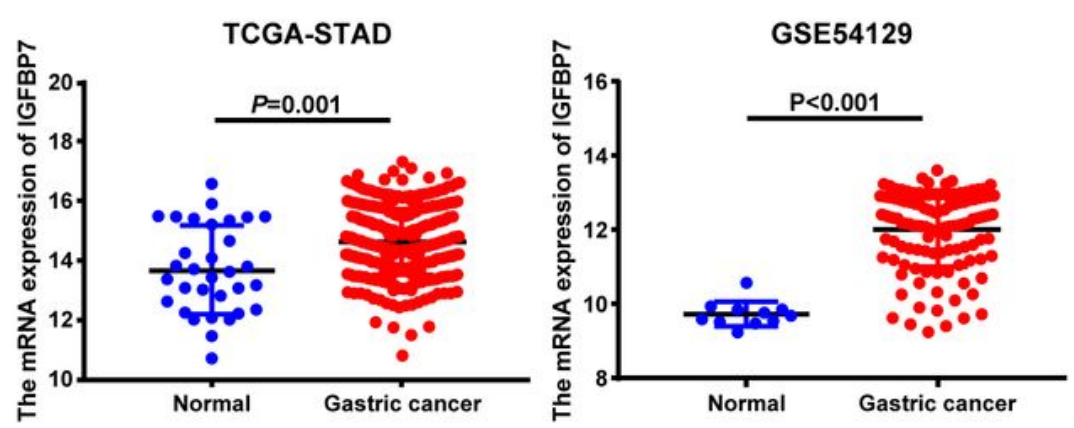

E

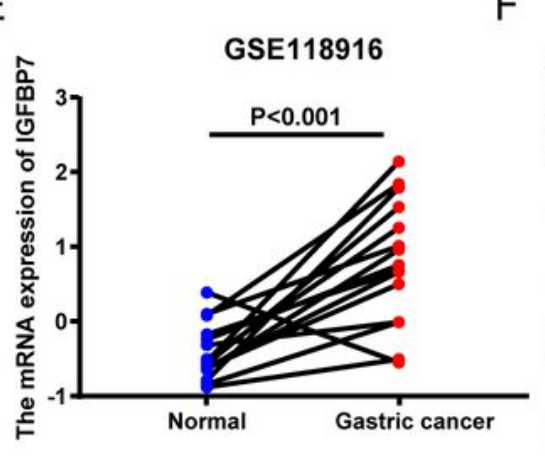

$\mathrm{F}$

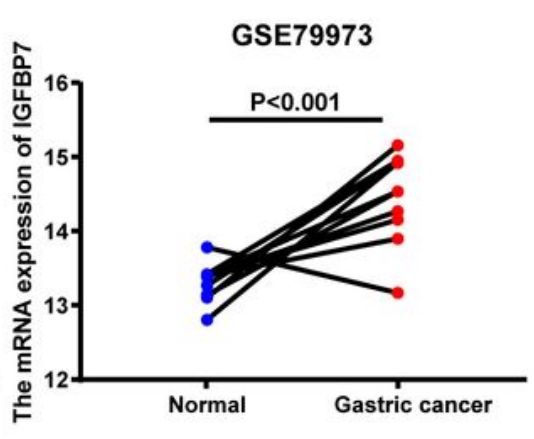

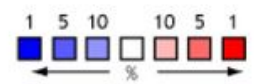

\section{Figure 1}

The transcription level of IGFBP7 was increased in gastric cancer. A, The expression of IGFBP7 in different types of cancers as assessed with the TIMER database. ${ }^{*}, P<0.05 ; * \star, P<0.01 ; * \star \star, P<0.001$. $B$, The expression of IGFBP7 in different types of cancers as assessed with the Oncomine database. Colors: red, high expression; blue, low expression. C-F, The expression of IGFBP7 in gastric cancer based on TCGA (C), GSE54129 (D), GSE118916 (E), and GSE79973 (F) datasets. 
A

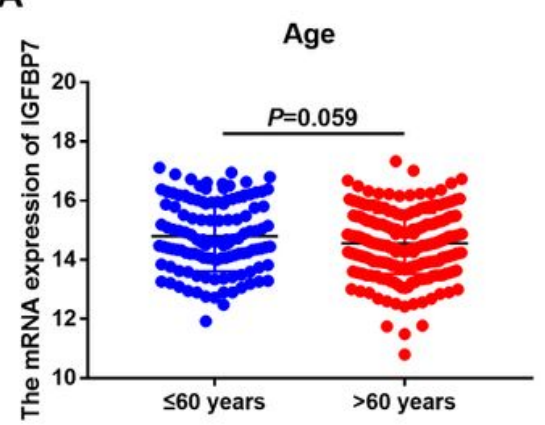

D

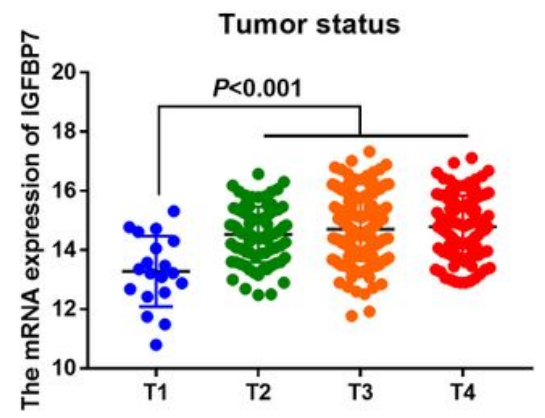

G

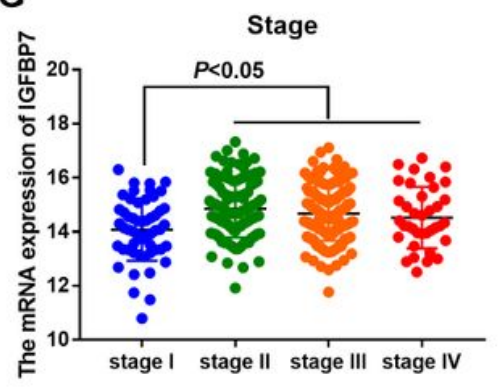

B

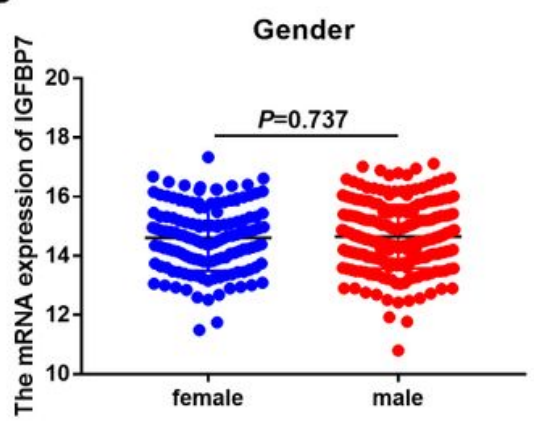

E

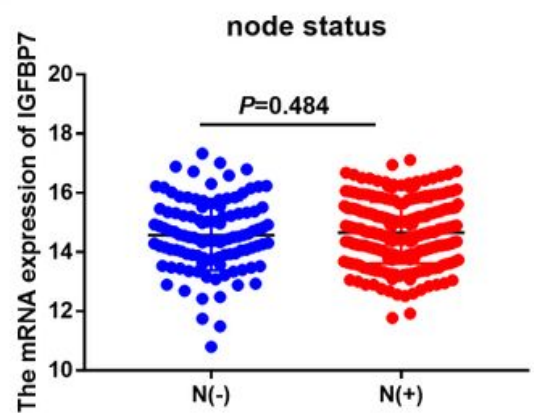

H

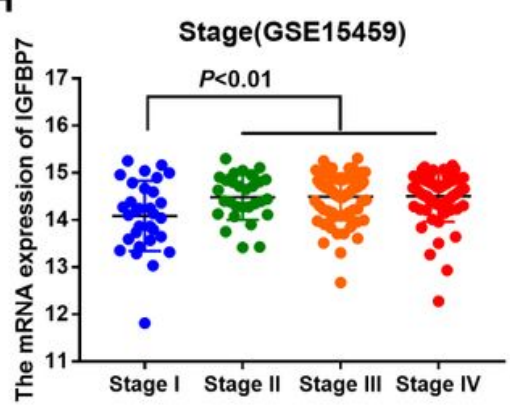

C

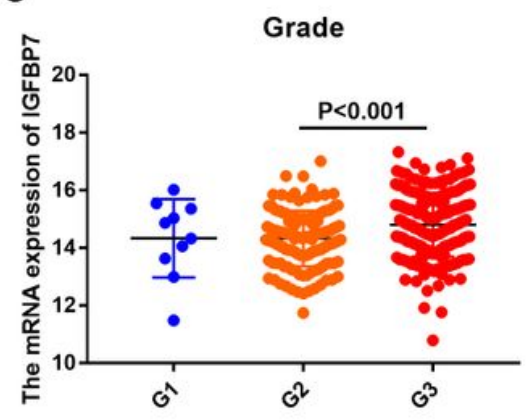

$\mathbf{F}$

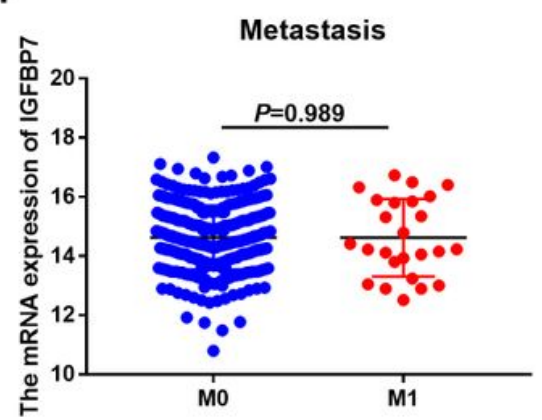

I

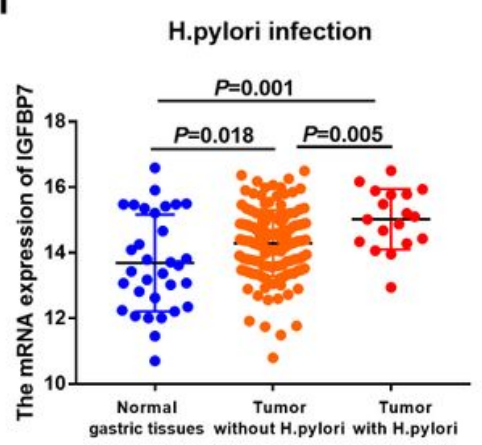

Figure 2

Association between IGFBP7 expression and clinicpathological characteristic of GC patients. The mRNA expression level of IGFBP7 is shown with scatter plots using the TCGA-STAD dataset according to age (A), sex (B), grade (C),tumor status (D), node status (E), metastasis $(F)$, stage $(G)$ and $H$. pylori infection (I), as well as according to stage in GSE15459 dataset $(\mathrm{H})$. 
A

OS

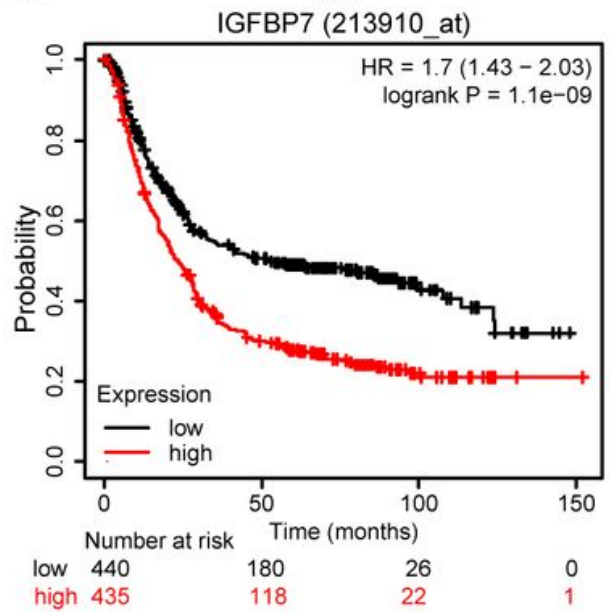

D

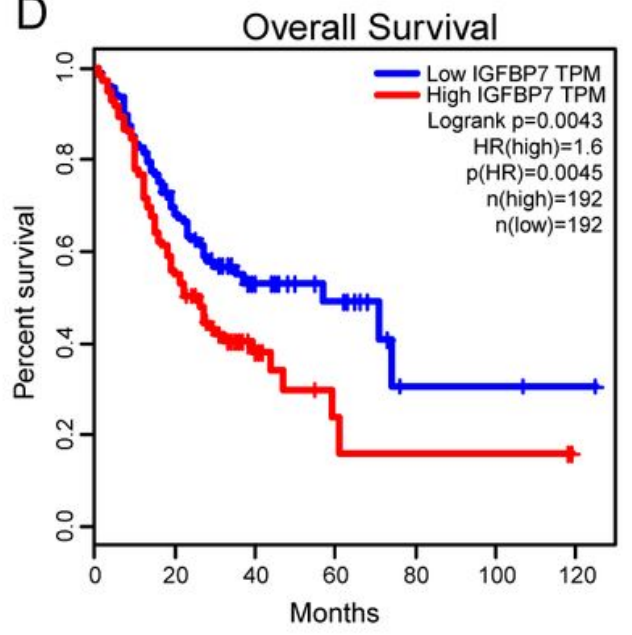

B

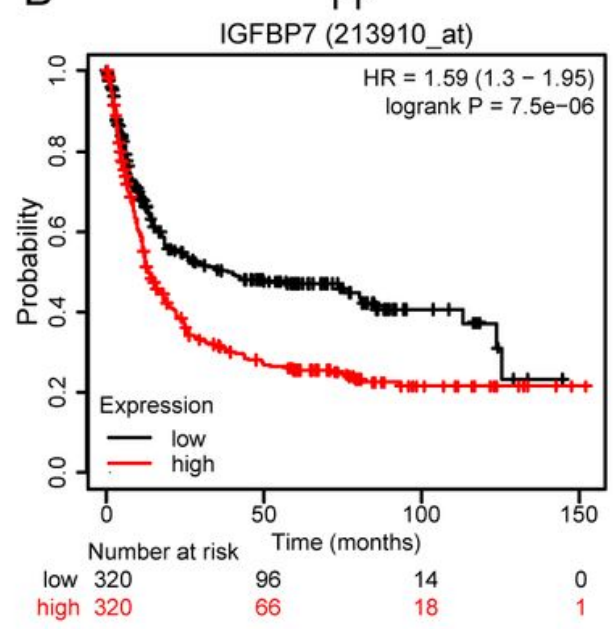

C

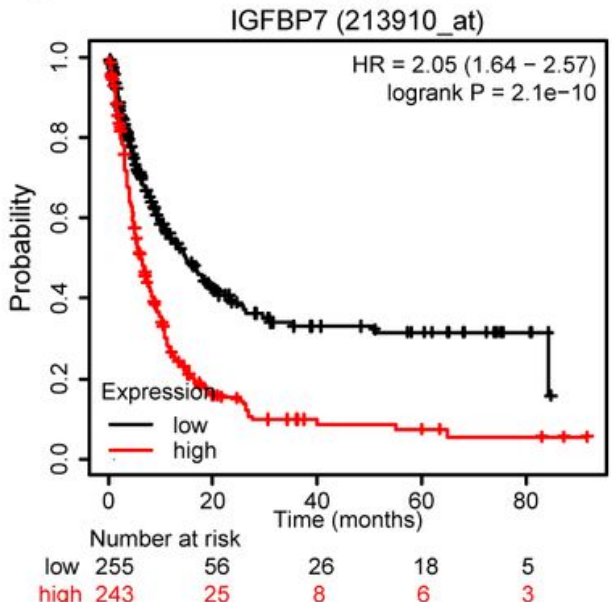

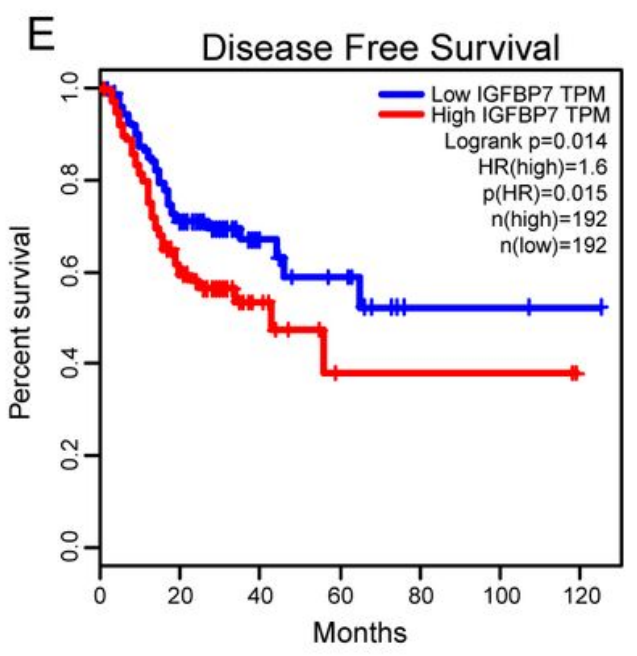

Figure 3

High IGFBP7 expression was associated with poor prognosis in GC. A-C, The relationship of IGFBP7 mRNA expression with overall survival (OS) (A), first progression survival (FPS) (B) and post progression survival (PPS) (C) was assessed with probe 213910_at in the Kaplan-Meier Plotter database. D-E, The association of IGFBP7 mRNA expression and overall survival (D) and disease-free survival (E) was assessed in the GEPIA database. The median value was used as the cutoff for dividing the high and low groups. 

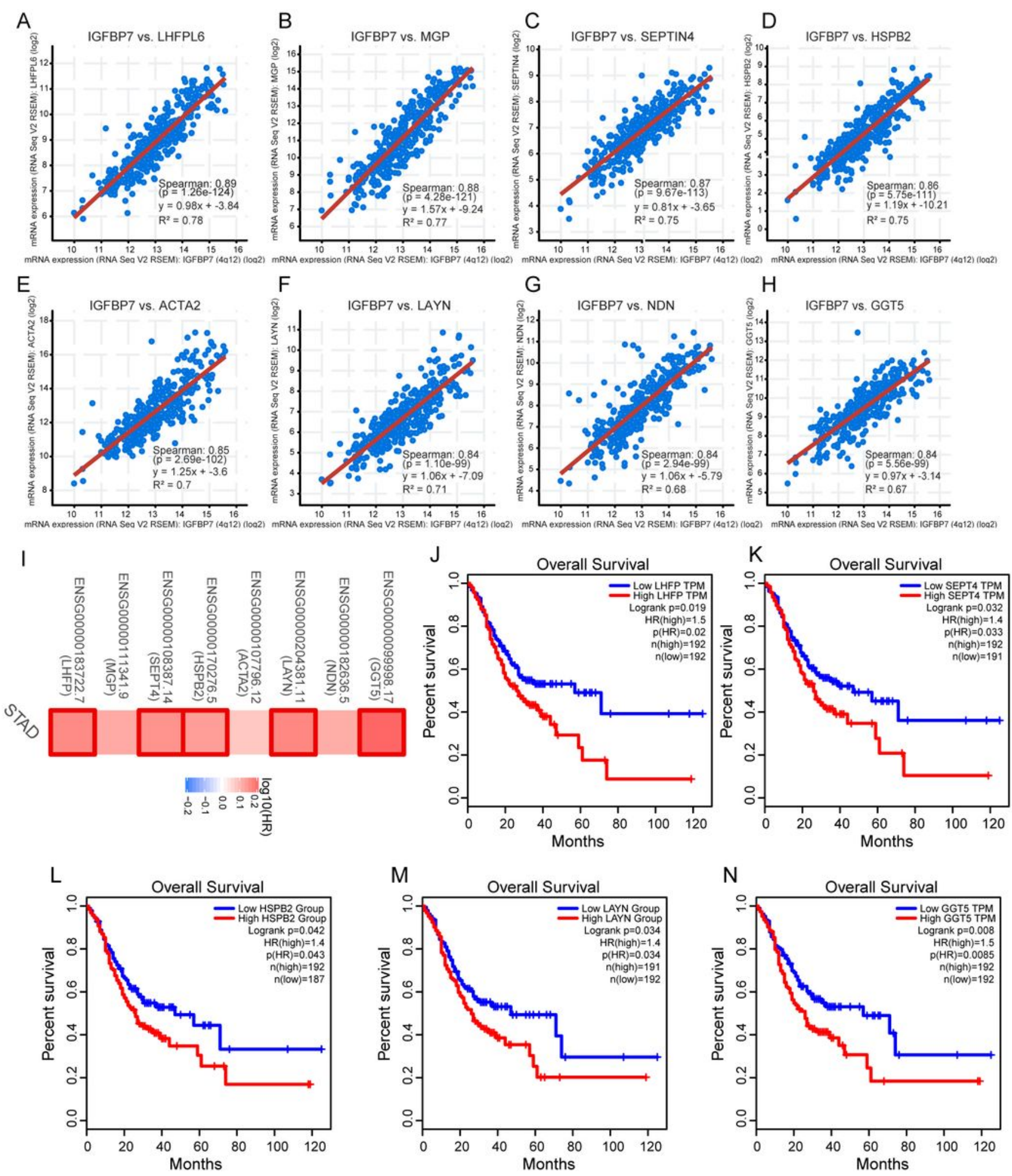

\section{Figure 4}

Analyses of genes coexpressed with IGFBP7. A-H, The top eight coexpressed genes of IGFBP7 were selected and correlation analysis was performed in the cBioPortal online database. These genes included LHFPL6 (A), MGP (B), SEPT4 (C), HSPB2 (D), ACTA2 (E), LAYN (F), NDN (G) and GGT5 (H). I, Survival map of the 8 coexpressed genes based on TCGA-STAD project data was generated with the GEPIA online tool. A red box indicates those genes with statistical significance. J-N, Overall survival analysis was performed 
for LHFPL6 (J), SEPT4 (K), HSPB2 (L), LAYN (M) and GGT5 (N). Briefly, GC samples were divided into high and low expression groups by the median expression value of the gene. The log-rank method was used for the hypothesis test.

A

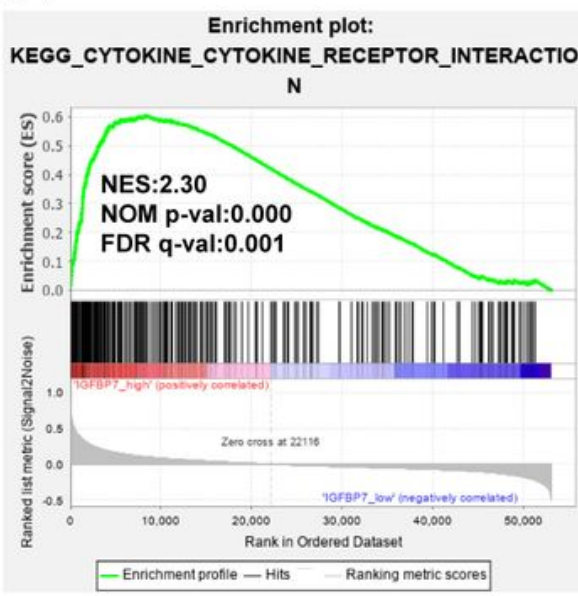

D

Enrichment plot: KEGG_ECM_RECEPTOR_INTERACTION

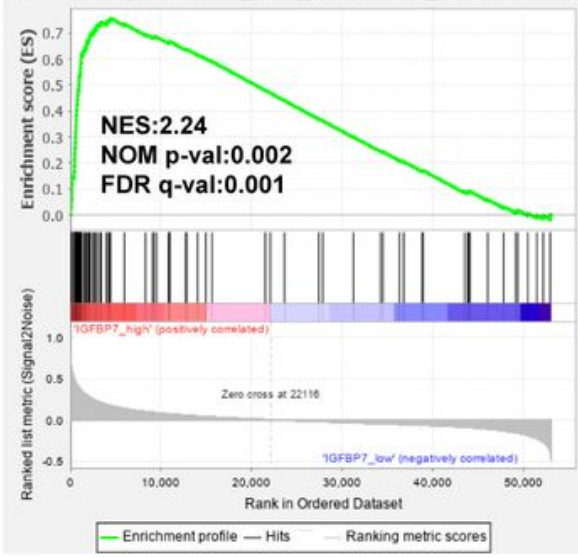

G

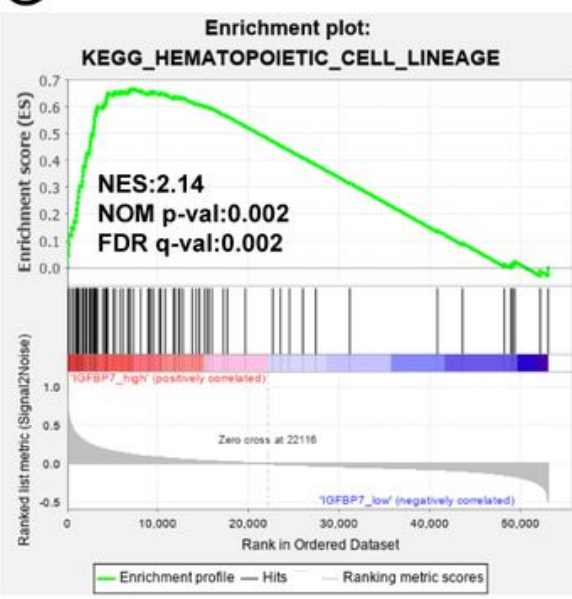

B

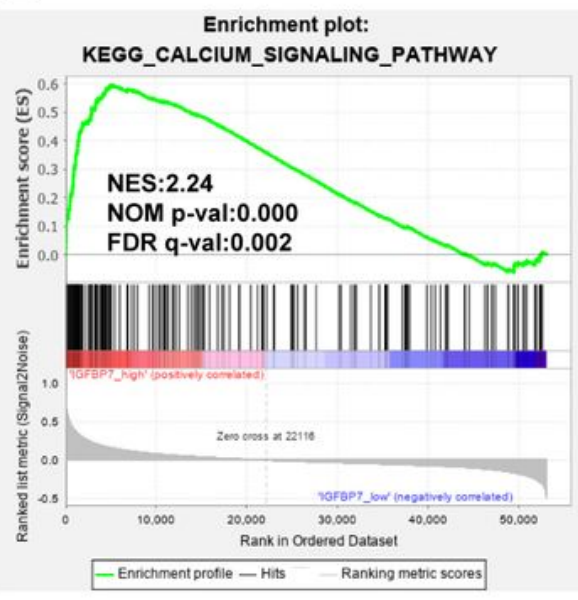

$E$

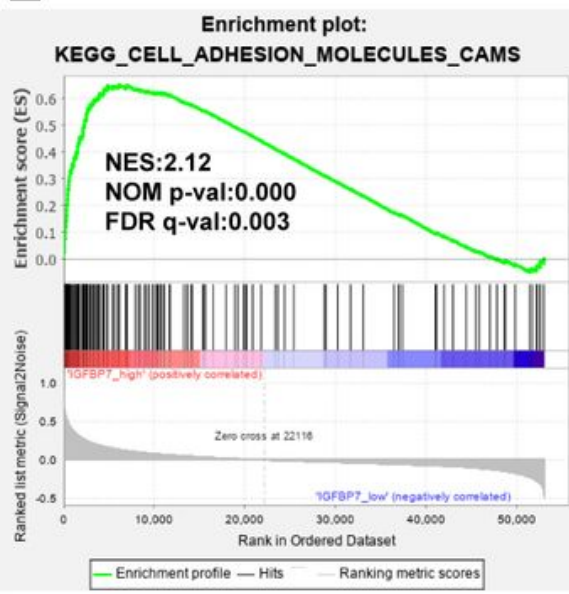

$\mathrm{H}$

Enrichment plot: KEGG_COMPLEMENT_AND_COAGULATION_CASCADES

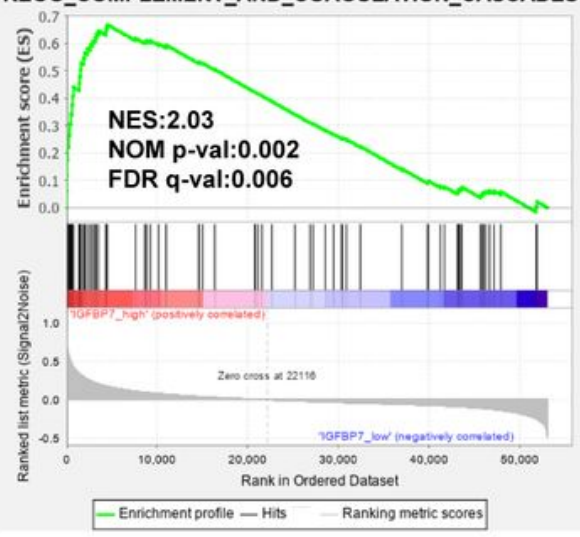

C

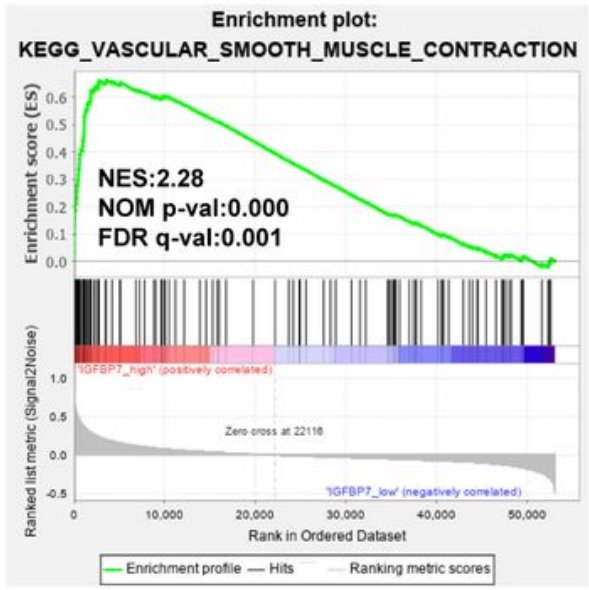

$\mathrm{F}$

Enrichment plot: KEGG_FOCAL_ADHESION
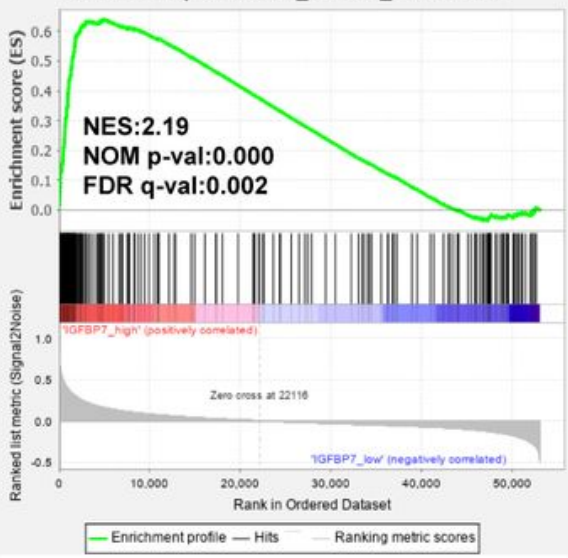

I

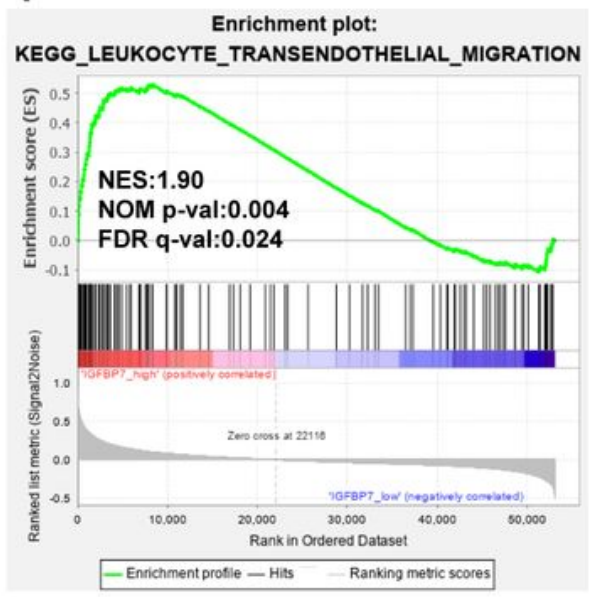

Figure 5

GSEA analysis of IGFBP7 based on expression in the TCGA-STAD dataset. NES: normalized enrichment score; NOM p-value: nominal p value; FDR q-val: false discovery rate. 

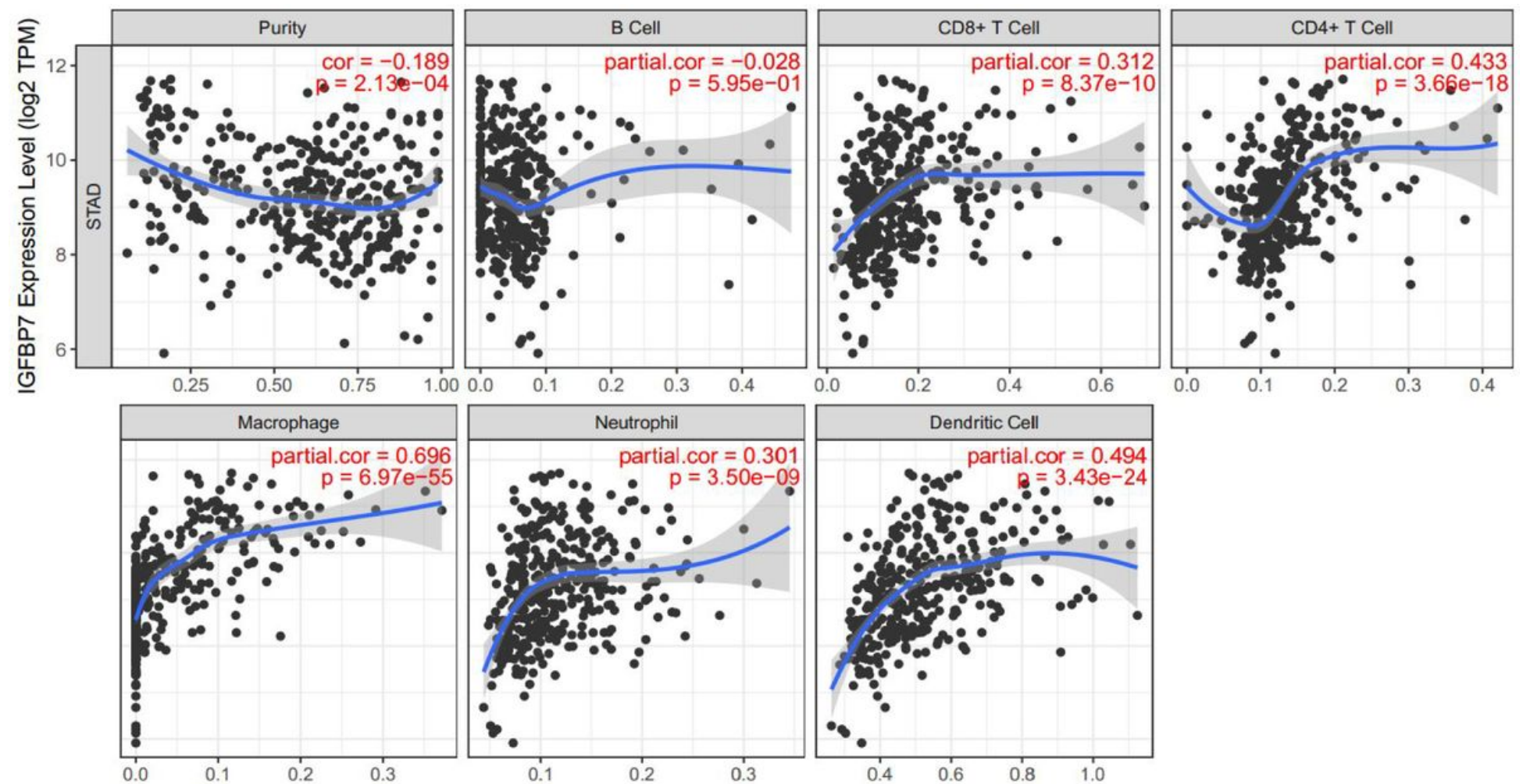

Figure 6

Correlation of IGFBP7 expression with immune cell infiltration in GC. The study was performed in the TIMER database. Spearman's correlation was used to evaluate the correlation between IGFIBP7 expression and immune cells.

\section{Supplementary Files}

This is a list of supplementary files associated with this preprint. Click to download.

- Supplementarymaterial.docx 